\title{
Bronchodilator response following methacholine-induced bronchoconstriction predicts acute asthma exacerbations
}

\author{
Heung-Woo Park ${ }^{1,2}$, Woo-Jung Song ${ }^{2}$, Yoon-Suk Chang ${ }^{3}$, Sang-Heon Cho ${ }^{2}$, \\ Soma Datta ${ }^{1}$, Scott T. Weiss ${ }^{1,4}$ and Kelan G. Tantisira ${ }^{1,5}$
}

Affiliations: ${ }^{1}$ The Channing Division of Network Medicine, Dept of Medicine, Brigham and Women's Hospital, Harvard Medical School, Boston, MA, USA. ${ }^{2}$ Dept of Internal Medicine, Seoul National University College of Medicine, Seoul, Republic of Korea. ${ }^{3}$ Dept of Internal Medicine, Seoul National University Bundang Hospital, Seongnam, Republic of Korea. ${ }^{4}$ Partners Center for Personalized Medicine, Partners Health Care, Boston, MA, USA. 'Division of Pulmonary and Critical Care Medicine, Dept of Medicine, Brigham and Women's Hospital, Boston, MA, USA.

Correspondence: Heung-Woo Park, Dept of Internal Medicine, Seoul National University College of Medicine, Seoul, Republic of Korea. E-mail: guinea71@isnu.ac.kr

ABSTRACT Methacholine bronchial provocation test provides the concentration of methacholine causing a $20 \%$ decrease in forced expiratory volume in $1 \mathrm{~s}$ (FEV1) from baseline (PC20). The doseresponse slope (DRS), and other continuous indices of responsiveness (CIR; the percentage decline from the post-diluent baseline FEV 1 after the last dose of methacholine), and per cent recovery index (PRI; the percentage increase from the maximally reduced $\mathrm{FEV} 1$ after bronchodilator inhalation) are alternative measures. The clinical relevance of these indices in predicting acute asthma exacerbations has not been fully evaluated.

In two prospective cohorts of childhood and elderly asthmatics, baseline PC20, DRS, CIR and PRI were measured and evaluated as predictors of acute asthma exacerbations.

We found that PRI was significantly related to the presence of asthma exacerbations during the first year of follow-up in both cohorts of childhood $(p=0.025)$ and elderly asthmatics $(p=0.003)$. In addition, PRI showed a significant association with the total number of steroid bursts during 4.3 years of follow-up in the cohort of childhood asthmatics $(\mathrm{p}=0.04)$.

We demonstrated that PRI, an index of reversibility following methacholine-induced bronchoconstriction, was a good clinical predictor of acute exacerbations of asthma in both childhood and elderly asthmatics.

@ERSpublications

Bronchodilator response following methacholine-induced bronchoconstriction may predict acute asthma exacerbations http://ow.ly/ZguI2

\footnotetext{
This article has supplementary material available from erj.ersjournals.com

Received: Nov 062015 | Accepted after revision: March 012016 | First published online: April 132016

Support statement: This work was supported by the National Institute of Health, US (R01 NR013391 and U01 HL065899) and by the Ministry of Health and Welfare, Republic of Korea (2008-E33028-00, 2009-E33022-00 and 2011-E33005-00). Funding information for this article has been deposited with FundRef.
}

Conflict of interest: Disclosures can be found alongside this article at erj.ersjournals.com

Copyright OERS 2016 


\section{Introduction}

In clinical practice, the methacholine bronchial provocation test (MBPT) is widely used to measure airway hyperresponsiveness (AHR), which is one of the defining features of asthma [1]. When we interpret the results of MBPT, we usually focus only on the threshold causing a $20 \%$ decrease in forced expiratory volume in $1 \mathrm{~s}(\mathrm{FEV} 1)$ from baseline (i.e. PC20 or PD20). However, MBPT provides us other metrics of AHR, such as dose-response slope (DRS; the per cent decline in FEV1 per methacholine dose) [2, 3], the continuous index of responsiveness (CIR; the per cent decline from the post-diluent baseline FEV 1 after the last dose of methacholine) [3] and the per cent recovery index (PRI; the per cent increase from the maximally reduced FEV1 after bronchodilator inhalation) [4]. DRS and CIR are indicators of airway responsiveness in the presence of a bronchoconstrictor and reflect the severity of response by assessing the intensity of bronchoconstriction [2,3]. In stable asthma, the health-related quality of life is not related to the sensitivity index (PC20) but rather to the reactivity index (DRS and CIR) [5]. PRI has been used to assess efficacy of anti-asthmatic drugs [6,7]. However, the clinical implications of these other metrics of AHR have not been fully evaluated.

Asthmatics sometimes experience an acute deterioration of symptoms, termed an "exacerbation". Even among asthmatics with controlled asthma, $43 \%$ had an unscheduled hospital visit, $10 \%$ had an emergency department visit and 3\% had a hospitalisation in the past year [8]. The social and economic burden of asthma exacerbations remains considerable $[9,10]$. Previously, we reported that pre-bronchodilator FEV 1 was negatively correlated with asthma exacerbation in asthmatic children [11]. Other physiological parameters that predict asthma exacerbations include forced expiratory flow between 25 and $75 \%$ of vital capacity in the setting of normal FEV1 [12], peripheral airway impulse oscillometry [13] and peak expiratory flow rate [14]. However, there have been no reports comprehensively showing the role of indices obtained from MBPT in predicting asthma exacerbations.

The purpose of this study was to evaluate the clinical utility of measures (PC20, DRS, CIR, and PRI) generated from MBPT in assessing the future risk of asthma exacerbations. For this, we investigated the relationship between baseline values of the MBPT indices and asthma exacerbations in two prospective cohorts composed of childhood and elderly asthmatics.

\section{Methods}

Each study was approved by the Institutional Review Board of the corresponding institution (Seoul National University Hospital, Seoul, Korea (number: 0812-045-266) and Brigham and Women's Hospital, Boston, MA, USA (number: 2004-P-000996) and informed consent was obtained from all study participants.

\section{Study populations}

The first cohort consisted of children from the Childhood Asthma Management Programme (CAMP) trial. CAMP demographics and study design have been described elsewhere $[15,16]$. A total of 1041 children with mild-to-moderate asthma aged 5-12 years were enrolled; a positive MBPT test $\left(\mathrm{PC} 20<12.5 \mathrm{mg} \cdot \mathrm{mL}^{-1}\right)$ was an entry criteria for the CAMP trial. At baseline, the number of hospitalisations or emergency room visits in the past 12 months was measured. The children were randomised to budesonide, nedocromil or placebo and followed for a mean of 4.3 years. The total number of prednisone bursts and the total number of hospitalisations or emergency room visit during the study period were calculated. An acute exacerbation was defined if patients experienced one or more prednisone bursts, hospitalisations or emergency room visits.

The second cohort consisted of elderly asthmatics aged $\geqslant 65$ years that were recruited from Seoul National University Hospital, Seoul and Bundang Seoul National University Hospital, Bundang, Korea. It was a subset of a prospective, observational multicentre cohort in Korea with the purpose of studying the natural history of asthma among elderly people [17]. History of a previous exacerbation (no versus yes) was assessed using a careful review of the medical records from 3 months before enrolment. Cognitive function was assessed using the Korean version of the Mini-Mental State Examination, and mood was assessed using the Korean version of the Geriatric Depression Scale Short Form. Proficiency in using inhaler devices was rated using a scoring system. After baseline evaluations, elderly adults with asthma who were enrolled were treated for 1 year with conventional medications based on the Global Initiative for Asthma guidelines [18]. Follow-up visits were scheduled every 3 months, and the occurrence of asthma exacerbations during the past 3 months was recorded at every visit. An asthma exacerbation was defined when one of the following criteria was satisfied: use of systemic corticosteroids for at least three successive days, asthma-specific unscheduled visits, and emergency department visits or hospitalisations.

\section{Methacholine bronchial provocation test and index analysed}

In the CAMP cohort, MBPT was carried out before randomisation using the method of 2 min of tidal breathing from a Wright nebuliser (Bayview Medical Supply, Baltimore, MD, USA) [19]. Children inhaled 
incrementally doubling doses of methacholine from 0.098 to $12.5 \mathrm{mg} \cdot \mathrm{mL}^{-1}$ until there was a $20 \%$ fall from the post-saline FEV1. Then a bronchodilator (two puffs of salbutamol) was administrated and FEV1 was measured $15 \mathrm{~min}$ after bronchodilator inhalation. In the elderly cohort, MBPT was carried out using the modified method described by CHAI et al. [20]. Concentrations of $1.25,2.5,6.25$, and $12.5 \mathrm{mg} \cdot \mathrm{mL}^{-1}$ of methacholine were prepared by dilution with buffered saline. A Rosenthal-French dosimeter (Laboratory for Applied Immunology, Baltimore, MD, USA) was used to deliver the aerosol generated by a DeVilbiss 646 nebuliser (Medical Depot, Inc., Port Washington, NY, USA). Subjects inhaled five inspiratory capacity breaths of increasing concentrations of methacholine until FEV1 fell by more than $20 \%$ of its baseline value. Then a bronchodilator (two puffs of salbutamol) was administrated and FEV1 was measured 15 min after bronchodilator inhalation.

Figure 1 shows how indices from the MBPT were calculated. PC20 was calculated by interpolation from the last two concentrations. DRS, CIR and PRI were calculated as follows:

$$
\begin{gathered}
\text { DRS }=\frac{(\text { Post-diluent FEV } 1-\text { FEV } 1 \text { at the last dose of methacholine })}{(\text { Post-diluent FEV } 1 \times \text { Last methacholine dose })} \times 100 \\
\text { CIR }=\frac{(\text { Post-diluent FEV } 1-\text { FEV } 1 \text { at the last dose of methacholine })}{\text { Post-diluent FEV } 1} \times 100 \\
\text { PRI }=\frac{(\text { Post-bronchodilator FEV } 1-\text { FEV } 1 \text { at the last dose of methacholine })}{(\text { Post-diluent FEV } 1-\text { FEV } 1 \text { at the last dose of methacholine })} \times 100
\end{gathered}
$$

All indices were natural log-transformed.

\section{Statistical analysis}

A regression analysis (with a logistic regression for the categorical variable and a linear regression for the continuous variable) was performed to evaluate the predictive roles of each index in both cohorts for exacerbations. In the CAMP cohort, age, sex (female versus male), body mass index (BMI) z-score, baseline FEV1 \% predicted, history of exacerbation during the previous 1 year (no versus yes), race (Caucasian versus African-American versus Hispanic-American versus Asian-American) and treatment group (placebo versus nedocromil versus inhaled corticosteroid) were included as covariates. The primary outcome was the presence of exacerbations within the first year (categorical variable). Secondary outcomes included per cent increase in FEV1 from the baseline value 8 weeks after treatment, and cumulative number of hospitalisations

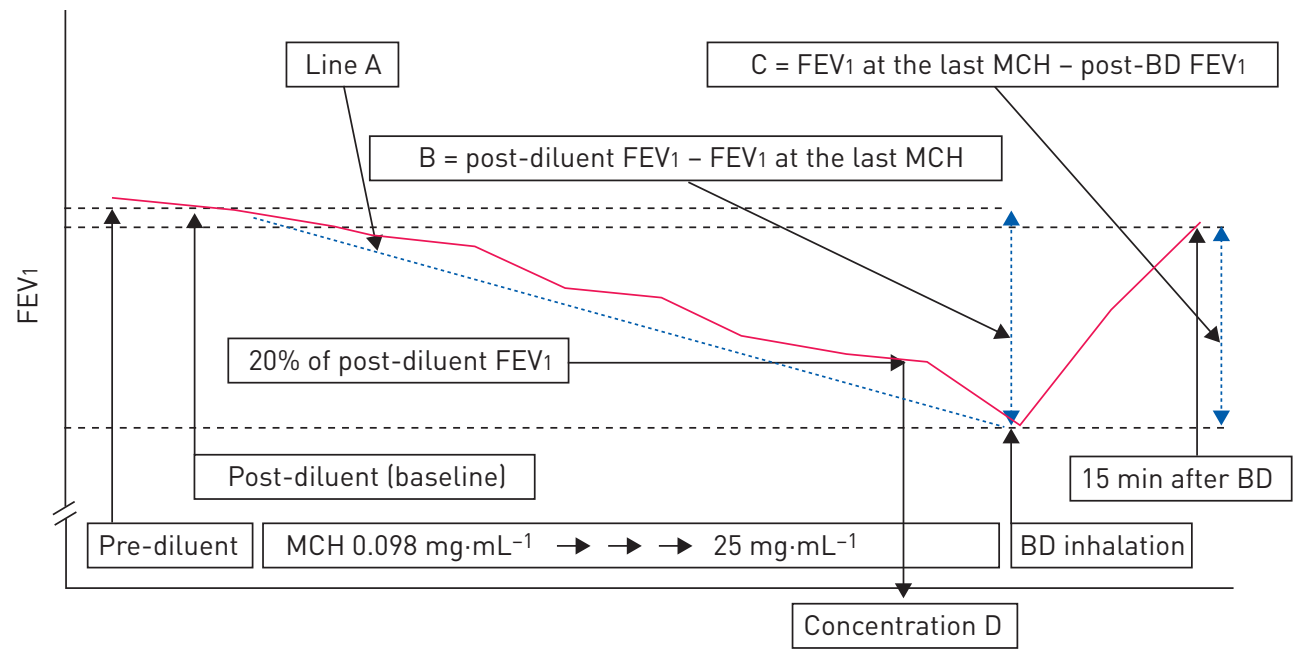

Dose-response slope $=$ slope of line $A$

$\mathrm{PC}_{20}=\mathrm{MCH}$ concentration at $\mathrm{D}$

Continuous index of responsiveness $=\left(B /\right.$ post-diluent $($ baseline $\left.) F E V_{1}\right) \times 100$

Per cent recovery index $=(\mathrm{C} / \mathrm{B}) \times 100$

FIGURE 1 Indices generated from the methacholine bronchial provocation test. FEV1: forced expiratory volume in $1 \mathrm{~s}$; $\mathrm{BD}$ : bronchodilator; $\mathrm{MCH}$ : methacholine; PC20: concentration of methacholine causing a $20 \%$ decrease in FEV1 from baseline. 
or emergency room visits at 4 years of follow-up (continuous variables). Covariates in the elderly asthma cohort included age, sex (female versus male), BMI, baseline FEV1 \% predicted, smoking status (no versus yes), history of exacerbation during previous 1 year (no versus yes), cognitive function, depression status and inhaler technique. As with CAMP, the primary outcome was the occurrence of exacerbations within 1 year after enrolment (categorical variable). A p-value of $<0.05$ was considered significant. All analyses were performed with $\mathrm{R}$ version 2.15 .3 (www.r-project.org). $\mathrm{R}$ scripts can be found in the online supplementary material.

\section{Results}

Table 1 summarises the baseline characteristics of the childhood and the elderly asthmatics.

\section{Cohort of childhood asthmatics}

Pearson's correlation coefficients were measured to assess interdependency of indices generated from MBPT at baseline. High correlations were noted except between $\ln (\mathrm{PC} 20)$ and $\ln (\mathrm{CIR})$ (table E1 and figure E1). To evaluate roles of each index in predicting clinical outcomes, regression models were constructed using age, sex, race, BMI z-score, FEV1 predicted value, treatment group, history of past exacerbation and the four indices of responsiveness. Using the variance inflation factor, we evaluated the severity of multicollinearity in our models. The variance inflation factor enables us to measure how much the variance of an estimated regression coefficient is increased because of collinearity [21]. By removing $\ln (\mathrm{DRS})$ from our models we could obtain acceptable variance inflation factor values $(<5)$ (table E2). Accordingly, $\ln (\mathrm{DRS})$ was excluded from the final model. The results of the regression analysis are presented in table $2 . \ln (\mathrm{PC} 20)$ and $\ln (\mathrm{PRI})$ showed significant associations with incident exacerbations at 1 year. The odds ratio obtained from logistic regression analysis was 2.23 (95\% CI 1.11-4.54). $\ln (\mathrm{PRI})$ also showed a significant association with cumulative numbers of steroid bursts at 4.3 years, but $\ln (\mathrm{PC} 20)$ did not. There were no other associations between MBPT indices and any of the other clinical outcomes.

\section{Cohort of elderly asthmatics}

Unlike childhood asthmatics, high correlations were noted among all pairs of MBPT indices (table E1 and figure E1). After collinearity diagnostics, the final logistic regression model included age, sex, BMI, baseline $\mathrm{FEV}_{1} \%$ predicted, smoking status, history of exacerbation during the previous 1 year, cognitive function, depression status, $\ln (\mathrm{PC} 20), \ln (\mathrm{DRS}), \ln (\mathrm{CIR})$ and $\ln (\mathrm{PRI})$ (table E3). Among the indices generated from $\mathrm{MBPT}$, only $\ln (\mathrm{PRI})$ was significantly associated with incident exacerbations at 1 year (table 3). The odds ratio obtained from logistic regression analysis was 59.88 (95\% CI 4.65-1228.76). Figure 2 shows that the $\ln (\mathrm{PRI})$ of asthmatics who experienced an acute exacerbations during the first year

\section{TABLE 1 Baseline characteristics}

\begin{tabular}{lcc} 
& Childhood asthmatics & Elderly asthmatics \\
\hline Subjects $\mathbf{n}$ & 736 & 145 \\
Age years & $8.9(7.2-10.6)$ & $68(65-72)$ \\
Male sex & $435(59.1)$ & $62(42.7)$ \\
FEV $\%$ predicted & $93(85-102)$ & $75(62-93)$ \\
BMI & $0.47(-0.21-1.28)^{\#}$ & $23.8(22.4-26.1)^{\pi}$ \\
Race & & \\
Caucasian & $495(67.3)$ & $0(0)$ \\
African-American & $109(14.8)$ & $0(0)$ \\
Hispanic & $68(9.2)$ & $0(0)$ \\
$\quad$ Asian & $64(8.7)$ & $145(100)$ \\
Smoking lyes) & $\mathrm{NA}$ & $46(31.7)$ \\
History of exacerbation (yes) & $228(31.0)$ & $18(12.4)$ \\
Treatment group & & \\
Inhaled corticosteroid & $230(31.3)$ & $\mathrm{NA}$ \\
$\quad$ Nedocromil & $206(28.0)$ & $\mathrm{NA}$ \\
Placebo & $300(40.7)$ & $\mathrm{NA}$ \\
Cognitive function score & $\mathrm{NA}$ & $27(24-29)$ \\
Depression score & $\mathrm{NA}$ & $6(3-10)$ \\
Inhaler technique score & $\mathrm{NA}$ & $5(5-6)$
\end{tabular}

Data are presented as median (interquartile range) or $\mathrm{n}(\%)$, unless otherwise stated. FEV 1 : forced expiratory volume in $1 \mathrm{~s}$; BMI: body mass index; NA: not applicable. ${ }^{\#}$ : $\mathrm{z}$-score; ${ }^{\text {n }}: \mathrm{kg} \cdot \mathrm{m}^{-2}$. 
TABLE 2 Relationships between the methacholine bronchial provocation test indices and clinical outcomes in the CAMP childhood asthmatics

\begin{tabular}{|c|c|c|c|c|c|c|c|c|}
\hline & \multicolumn{2}{|c|}{$\begin{array}{l}\text { Experience of exacerbation } \\
\text { at } 1 \text { year (no versus yes) }\end{array}$} & \multicolumn{2}{|c|}{ FEV 1 increase at 8 weeks ${ }^{\pi}$} & \multicolumn{4}{|c|}{ Cumulative number of events at 4 years } \\
\hline & \multirow[b]{2}{*}{$\beta$ coefficient } & \multirow[b]{2}{*}{ p-value } & \multirow[b]{2}{*}{$\beta$ coefficient } & \multirow[b]{2}{*}{ p-value } & \multicolumn{2}{|c|}{ ER/hospital visit" } & \multicolumn{2}{|c|}{ Steroid burst ${ }^{\pi}$} \\
\hline & & & & & $\beta$ coefficient & p-value & $\beta$ coefficient & p-value \\
\hline Age & -0.163 & $3.91 \times 10^{-5}$ & -0.114 & 0.562 & -0.040 & 0.185 & -0.269 & $2.50 \times 10^{-4}$ \\
\hline Sex_male & 0.050 & 0.755 & 0.665 & 0.416 & -0.013 & 0.917 & 0.107 & 0.721 \\
\hline Race_African-American & -0.068 & 0.770 & 1.172 & 0.317 & 0.409 & 0.022 & -0.016 & 0.970 \\
\hline Race_Hispanic & 0.143 & 0.608 & -0.301 & 0.830 & 0.138 & 0.520 & 0.564 & 0.278 \\
\hline Race_Asian & 0.358 & 0.220 & -1.280 & 0.370 & 0.180 & 0.408 & 0.755 & 0.153 \\
\hline BMI z-score & -0.078 & 0.308 & -0.406 & 0.288 & 0.016 & 0.772 & -0.453 & $1.41 \times 10^{-3}$ \\
\hline FEV $_{1} \%$ predicted & 0.005 & 0.453 & 0.003 & 0.915 & 0.007 & 0.171 & -0.011 & 0.359 \\
\hline Treat_nedocromil & -0.181 & 0.355 & -0.071 & 0.942 & -0.339 & 0.022 & -1.224 & $7.26 \times 10^{-4}$ \\
\hline Treat_ICS & -0.926 & $9.63 \times 10^{-7}$ & 5.593 & $4.47 \times 10^{-9}$ & -0.518 & $3.43 \times 10^{-4}$ & -2.166 & $8.92 \times 10^{-10}$ \\
\hline History of acute exacerbation_yes & 0.647 & $3.33 \times 10^{-4}$ & -1.068 & 0.224 & 0.093 & $9.49 \times 10^{-12}$ & 1.710 & $1.86 \times 10^{-7}$ \\
\hline $\ln \left(P C_{20}\right)$ & -0.216 & $7.99 \times 10^{-3}$ & -0.008 & 0.984 & -0.074 & 0.232 & -0.178 & 0.236 \\
\hline $\ln (\mathrm{CIR})$ & -0.304 & 0.346 & -0.136 & 0.933 & 0.259 & 0.297 & 0.310 & 0.605 \\
\hline $\ln (P R I)$ & 0.803 & 0.025 & 1.147 & 0.515 & 0.373 & 0.232 & 1.341 & 0.039 \\
\hline
\end{tabular}

CAMP: Childhood Asthma Management Programme; FEV1: forced expiratory volume in $1 \mathrm{~s}$; ER: emergency room; BMI: body mass index; ICS: inhaled corticosteroid; PC20: concentration of methacholine causing a $20 \%$ decrease in FEV1 from baseline; CIR: continuous index of response; PRI: per cent recovery index. Data in bold indicates statistically significant results ( $p<0.05)$. \#: Logistic regression analysis. A negative $\beta$ coefficient means that the odds ratio is less than one. १: Linear regression analysis. 
TABLE 3 Relationship between variables and acute exacerbations in the cohort of elderly asthmatics

\begin{tabular}{|c|c|c|}
\hline & \multicolumn{2}{|c|}{$\begin{array}{c}\text { Experience of acute } \\
\text { exacerbation at } 1 \text { year (no versus yes) }{ }^{\#}\end{array}$} \\
\hline & $\beta$ coefficient & p-value \\
\hline Age & 0.045 & 0.401 \\
\hline Sex_male & -1.175 & 0.179 \\
\hline BMI & -0.101 & 0.258 \\
\hline Smoking status_yes & 1.651 & 0.043 \\
\hline FEV $1 \%$ predicted & -0.016 & 0.412 \\
\hline History of acute exacerbation_yes & 1.549 & 0.091 \\
\hline Cognitive function & 0.022 & 0.802 \\
\hline Depression & 0.172 & 0.062 \\
\hline $\ln \left(P_{20}\right)$ & 0.292 & 0.359 \\
\hline ln(DRS) & 0.727 & 0.696 \\
\hline $\ln (\mathrm{CIR})$ & 0.165 & 0.886 \\
\hline $\ln (P R I)$ & 4.079 & $3.43 \times 10^{-3}$ \\
\hline
\end{tabular}

BMI: body mass index; FEV1: forced expiratory volume in 1 s; PC20: concentration of methacholine causing a $20 \%$ decrease in FEV1 from baseline; DRS: dose-response slope; CIR: continuous index of response; PRI: per cent recovery index. Data in bold indicates statistically significant results ( $p<0.05)$. \#: Logistic regression analysis.

of follow-up was significantly higher when compared with $\ln (\mathrm{PRI})$ of those who did not in both cohorts of childhood and elderly asthmatics. Comparisons of the characteristics between the two groups in both cohorts are presented in table E4 and E5.

\section{Discussion}

MBPT is easy to perform and thus is widely used in clinical practice to diagnose asthma. In the present study, we evaluated the role of four measures (PC20, DRS, CIR and PRI) obtained from MBPT in predicting future risk of asthma exacerbations. We found that PRI, the degree of response to bronchodilator after methacholine-induced bronchoconstriction, was significantly related to the occurrence of asthma exacerbations within 1 year of follow-up in two prospective cohorts of childhood and elderly asthmatics. In addition, PRI showed a significant association with the total number of steroid bursts within 4.3 years of follow-up in the cohort of childhood asthmatics. Of note, while PRI was a predictive marker of exacerbations in both children and elderly adults, the magnitude of effect was higher in the elderly adult cohort (OR 2.2 versus 59.9 for children versus adults, respectively), suggesting particular prognostic and therapeutic relevance in that cohort. Recently, it was reported that DRS showed clinical advantages over PC20 for the
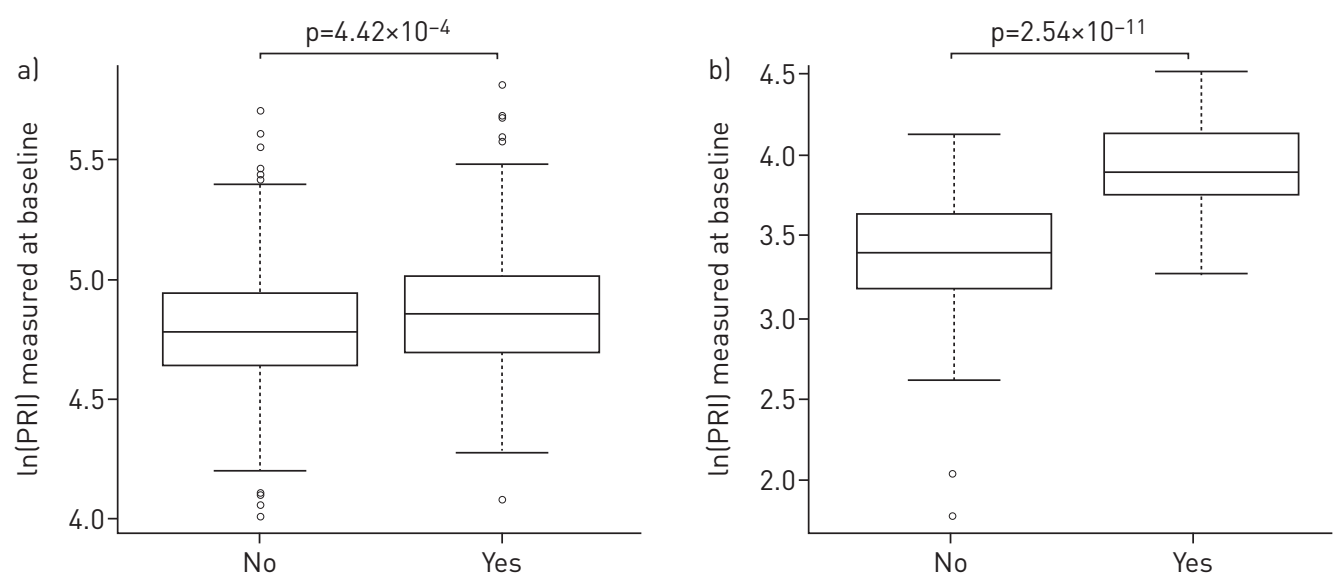

FIGURE 2 Comparison of the natural logarithm of per cent recovery index ( $\ln (\mathrm{PRI})$ ) between asthmatics who experienced acute exacerbations during the first year of follow-up and asthmatics who did not experience an acute exacerbation. a) Childhood asthmatics. b) Elderly asthmatics. The horizontal lines represent the median and boxes represent the interquartile range (IQR; Q1-Q3). Whiskers represent Q1-1.5xIQR (lower) and Q3+1.5×IQR (upper). 
prediction of development of asthma, chronic obstructive pulmonary disease and allergic rhinitis in the general population [22]. Clinically, it seems that DRS may be more important in subjects without definite AHR defined by PC20. However, in asthmatics, DRS was tightly correlated with PC20 as our results showed and thus may have no more clinical relevence than PC20. To the best of our knowledge, this is the first study to show a promising role for bronchodilator response following methacholine-induced bronchoconstriction in predicting asthma exacerbations.

Early reports showed that the degree of airway sensitivity and responsiveness to methacholine (PC20, DRS and CIR in this study) could be markers of asthma severity [23-25]. It is natural to expect that asthmatics with increased airway sensitivity and responsiveness are more susceptible to bronchoconstriction when they are exposed to nonspecific stimuli. However, it was reported that inhaled corticosteroid treatment gradually decreased airway hypersensitivity and hyperresponsiveness [26, 27]. These findings suggested that airway sensitivity and responsiveness index measured at baseline could not predict future asthma exacerbations as long as proper medications were provided. Hancox et al. [4] first introduced the challenge-rescue technique to assess bronchodilator response. Similar to the present study, they measured bronchodilator response after airway smooth muscle contraction induced by methacholine. PRI reflects the efficacy of bronchodilator medications in the environment causing maximal contraction of airway smooth muscle, as shown in the previous study [6, 7]. Airway smooth muscle of asthma patients was found to be abnormal in its functional properties and showed intrinsic heightened contractility independent of other structural cells and independent of the airway inflammatory milieu $[28,29]$. At present, we cannot measure how much airway smooth muscle contraction contributes to AHR. Recent studies, which showed that anti-IgE or anti-interleukin-5 antibodies in addition to inhaled corticosteroids further improved inflammation but did not affect AHR, implied that a bronchodilator might have its own role in the management of asthma [30-32]. In addition, we observed that PRI was not associated with airway eosinophilic inflammation of elderly asthmatics (figure E2). Taken together, we may assume that sufficient bronchodilator treatment is important for the effective management of asthmatics with high PRI. In CAMP, 5\% of asthmatic children randomised to the inhaled corticosteroid arm showed consistent bronchodilator responses over the 4-year trial and they had more hospital visits and required more prednisone bursts [33]. It is possible that maintenance treatments of bronchodilator were essential in certain cases. Namely, asthmatic children with a high PRI should have been managed with maintenance treatments of bronchodilator, including a combination therapy with inhaled corticosteroid and long-acting $\beta_{2}$-agonist, to reduce acute exacerbations. Another possible explanation is that asthmatic children with a high PRI might feel better symptomatic improvement compared with those with a low PRI when they used a short-acting $\beta_{2}$-agonist as a reliever medication. Actually, we found a positive correlation with a borderline significance $(\mathrm{p}=0.043)$ between $\ln (\mathrm{PRI})$ and the use of salbutamol (a short-acting $\beta_{2}$-agonist) during the first 8 weeks of follow-up in the CAMP childhood asthmatics (figure E3). As noted previously, an effective bronchodilation through a short-acting $\beta_{2}$-agonist therapy might mask symptoms of deteriorating asthma and lead to asthma exacerbations [34].

The elderly asthma cohort were treated with a combination of inhaled corticosteroid and bronchodilator (a long-acting $\beta_{2}$-agonist) as recommended by the current guidelines [18]. Despite a long-acting $\beta_{2}$-agonist therapy, a subset of this cohort continued to have an elevated PRI with very high likelihood of subsequent exacerbations (OR 59.88 (95\% CI, 4.65-1228.76)). We postulate that a maintenance treatment of long-acting $\beta_{2}$-agonist was not sufficient for elderly asthmatics with a high PRI. AHR was persistently observed even in the absence of airway inflammation following long-term use of ICS [35], which suggested that other pathophysiological factors, such as increased cholinergic and smooth muscle tone, might have a role in asthma [36, 37]. In accordance, tiotropium, a long-acting anti-cholinergic, as add-on to inhaled corticosteroid plus long-acting $\beta_{2}$-agonist, was found to be associated with a reduction in the number of asthma exacerbations $[38,39]$. Therefore, it was possible that intensive bronchodilator treatments including long-acting $\beta_{2}$-agonists and long-acting anti-cholinergic agents would be needed for elderly asthmatics with high PRI.

The present study has notable strengths and weaknesses. The clinical relevancy of PRI was demonstrated in two populations at the extremes of age, that is, childhood and elderly asthmatics. As pulmonary function testing is known to be affected by age [40,41], there may be concerns as to the accuracy of pulmonary function measurement in these extreme groups. However, preschool children and the elderly were capable of performing spirometry under the supervision of well-trained technicians [41-43]. Thus, the data in the present study are of high quality. A prospective study design of two cohorts is one of the strengths of the present study. However, we did not confirm that PRI is an invariant characteristic after long-term asthma treatments. If PRI improved after long-term asthma treatments, the clinical relevance of PRI measured at baseline in predicting asthma exacerbations would decrease as shown by a rise in the baseline PC20. In addition, an ethnicity difference needs to be considered in generalising our observations. Most subjects in the childhood cohort were Caucasian or African-American, but the elderly cohort was entirely Asian. A difference in ethnicity introduces both possible environmental and genetic variation and 
potentially alters the therapeutic efficacy of bronchodilators [44]. Finally, statistical issues need to be considered. The data used in the present study were gathered for another purpose and thus multiple testing was prone to type I errors. Bonferroni correction (multiplied by four (four comparable dependent variables)) effaced the significance of $\ln (\mathrm{PRI})$. In addition, it has been reported that logistic regression analysis in studies with a small sample size overestimated odds ratios [45]. The high odds ratio in elderly asthmatics should be reassessed in another cohort.

In conclusion, we demonstrated that PRI, an index of bronchodilator response following methacholine-induced bronchoconstriction, was a good clinical factor for predicting acute asthma exacerbations in both childhood and elderly asthmatics. An intensive bronchodilator treatment including a long-acting anti-cholinergic agent may be necessary for asthmatics with a high PRI.

\section{Acknowledgements \\ CAMP credit roster}

Source of funding: the CAMP trial and CAMP continuation study were supported by contracts NO1-HR-16044, 16045, 16046, 16047, 16048, 16049, 16050, 16051, and 16052 with the National Heart, Lung, and Blood Institute and General Clinical Research Center grants M01RR00051, M01RR0099718-24, M01RR02719-14, and RR00036 from the National Center for Research Resources. The CAMP continuation study/phases 2 and 3 were supported by grants U01HL075232, U01HL075407, U01HL075408, U01HL075409, U01HL075415, U01HL075416, U01HL075417, U01HL 075419, U01HL075420, and U01HL075408 from the National Heart, Lung, and Blood Institute.

\section{Members of the CAMP Research Group \\ Clinical centers}

ASTHMA, Inc., Seattle, WA, USA: Paul Williams (Principal investigator); Mary V. Lasley (Co-director); Tamara Chinn (Coordinator); Michele Hinatsu; Clifton T. Furukawa; Leonard C. Altman; Frank S. Virant; Michael S. Kennedy; Jonathan W. Becker; Stephen Tilles; Miranda MacLaren. C. Warren Bierman (1992-1997); Dan Crawford (1996-2002); Thomas DuHamel (1991-2004); Heather Eliassen (1996-1999); Babi Hammond (1996-1999); Dominick A. Minotti (1992-2003); Chris Reagan (1992-2003); Gail Shapiro (1991-2006, Principal investigator); Marian Sharpe (1992-1994); Ashley Tatum (2004-2007); Grace White (1991-2007); Timothy G. Wighton (1994-1998).

Brigham and Women's Hospital, Boston, MA, USA: Anne Fuhlbrigge (Principal investigator); Anne Plunkett (Coordinator). Nancy Madden; Mark Boehnert; Christine Darcy; Anita Feins; Natalia Kandror; Kelly MacAulay; Scott Weiss; Walter Torda (Co-investigator director, 1993-2003); Martha Tata (1993-2002); Sally Babigian (1997-1999); Peter Barrant (2004-2007); Linda Benson (1998-2004); Jose Caicedo (1998-1999); Tatum Calder (1998-2001); Anthony DeFilippo (1994-2000); Cindy Dorsainvil (1998-2001); Julie Erickson (1998-1999); Phoebe Fulton (1997); Mary Grace (1994-1996); Jennifer Gilbert (1997-1998); Dirk Greineder (1993-2000); Stephanie Haynes (1993-1998); Margaret Higham (1996-1998); Deborah Jakubowski (1999); Susan Kelleher (1993-1997); Jay Koslof (1993-1995); Dana Mandel (1996-1998); Patricia Martin (2001-2003); Agnes Martinez (1994-1997); Jean McAuliffe (1994-1995); Erika Nakamoto (2002-2004); Paola Pacella (1993-1998); Paula Parks (1993-1995); Johanna Sagarin (1998-1999); Kay Seligsohn (1995-2004); Susan Swords (2003-2005); Meghan Syring (1998-2001); June Traylor (1996-1998); Melissa Van Horn (1996-1999); Carolyn Wells (1993-1995); Ann Whitman (1994-1996).

The Hospital for Sick Children, Toronto, ON, Canada: Hartmut Grasemann (Principal investigator); Melody Miki (Coordinator); Melinda Solomon; Padmaja Subbarao. Ian MacLusky (Director 1999-2007); Joe Reisman (Director, 1996-1999); Henry Levison (Director, 1992-1996); Anita Hall (Coordinator, 19932007). Yola Benedet (1994-1999); Susan Carpenter (1998-2001); Jennifer Chay (2004); Michelle Collinson (1994-1998); Jane Finlayson-Kulchin (1994-1998); Kenneth Gore (1993-1999); Nina Hipolito (2003-2004); Noreen Holmes (1998-1999); Erica Hoorntje (2002-2003); Sharon Klassen (1999-2000); Josee Quenneville (1993-1995); Renee Sananes (1993-2004); Christine Wasson (1999); Margaret Wilson (2001-2002).

Johns Hopkins Asthma and Allergy Center, Baltimore, MD, USA: N. Franklin Adkinson, Jr (Director); Deborah Bull (Coordinator); Stephanie Philips. Peyton Eggleston (Co-director, 1991-2004); Karen Huss (Co-investigator, 1991-2004); Leslie Plotnick (Co-investigator, 1991-1999); Margaret Pulsifer (Co-investigator, 1993-2004); Cynthia Rand (Co-Investigator, 1991-2004). Elizabeth Aylward (1991-2004), Nancy Bollers (Coordinator, 1993-2004); Kathy Pessaro (2004-2007); Barbara Wheeler (Coordinator, 1991-1999).

National Jewish Health, Denver, CO, USA: Stanley Szefler (Director); Harold S. Nelson (Co-director); Bruce Bender (Co-investigator); Ronina Covar (Co-investigator); Andrew Liu (Co-investigator); Joseph Spahn (Co-investigator); D. Sundstrom (Coordinator); Melanie Phillips; Michael P. White; Melanie Gleason; Marzena Krawiec; Gary Larsen; Gayle Spears. Kristin Brelsford (1997-1999); Jessyca Bridges (1995-1997); 
Jody Ciacco (1993-1996); Michael Eltz (1994-1995); Jeryl Feeley (Coordinator, 1992-1995); Michael Flynn (1995-1996); Tara Junk-Blanchard (1997-2000); Joseph Hassell (1992-1998); Marcia Hefner (1992-1994); Caroline Hendrickson (1995-1998; Coordinator, 1995-1997); Daniel Hettleman (1995-1996); Charles G. Irvin (1992-1998); Alan Kamada (1994-1997); Sai Nimmagadda (1993-1996); Kendra Sandoval (1995-1997); Jessica Sheridan (1994-1995); Trella Washington (1993-1997); Eric Willcutt (1996-1997). We also thank the paediatric allergy/immunology and pulmonary fellows for their participation (Ivan Cardona; Kirstin Carel; Jayna Doshi; Rich Hendershot; Jeffrey Jacobs; Neal Jain; June-ku Brian Kang; Tracy Kruzick; Harvey Leo; Beth Macomber; Jonathan Malka; Chris Mjaanes; John Prpich; Lora Stewart; Ben Song; Grace Tamesis).

University of California, San Diego, and Kaiser Permanente Southern California Region, San Diego, CA, USA: Robert S. Zeiger (Director); Noah Friedman (Co-investigator); Michael H. Mellon (Co-investigator); Michael Schatz (Co-investigator); Kathleen Harden (Coordinator). Terrie Long; Travis Macaraeg; Elsa Rodriguez; Eva Rodriguez. Sandra Christensen (2004-2007); James G. Easton (Co-director, 19931994); M. Feinberg (1997-1998); Linda L. Galbreath (1991-2002); Jennifer Gulczynski (1998-1999); Ellen Hansen (1995-1997); Al Jalowayski (Co-investigator, 1991-2005); Elaine Jenson (2004-2007); Alan Lincoln (Co-investigator, 1991-2003); Jennie Kaufman (1994); Shirley King (1992-1999); Brian Lopez (1997-1998); Michaela Magiari-Ene (1994-1998); Kathleen Mostafa (1994-1995); Avraham Moscona (1994-1996); Catherine A. Nelle (1991-2005); Jennifer Powers (2001-2003); Karen Sandoval (1995-1996); Nevin W. Wilson (Co-director, 1991-1993).

University of New Mexico, Albuquerque, NM, USA: H. William Kelly (Director); Aaron Jacobs (Co-investigator); Hengameh H. Raissy (Co-investigator); Mary Spicher (Coordinator); Christina Batson; Robert Annett (Co-investigator, 1993-2004); Teresa Archibeque (1994-1999); Naim Bashir (Co-investigator, 1998-2005); H. Selda Bereket (1995-1998); Marisa Braun (1996-1999); Carrie Bush (1995-1999); Shannon C. Bush (2002-2007); Michael Clayton (Co-investigator, 1999-2001); Angel Colon-Semidey (Co-investigator, 1997-2000); Sara Devault (1993-1997); Anna Esparham (2004-2007); Roni Grad (Co-investigator, 1993-1995); David Hunt (1995-2004); Jeanne Larsson (1995-1996); Katie McCallum (2009); Sandra McClelland (Coordinator, 1993-1995); Bennie McWilliams (Co-investigator, Director, 19921998); Elisha Montoya (1997-2000); Margaret Moreshead (1996-1999); Shirley Murphy (Co-investigator, 1992-1994); Barbara Ortega (1993-1999); David Weers (1997-1998); Jose Zayas (1995-1996).

Washington University, St Louis, MO, USA: Robert C. Strunk (Director); Leonard Bacharier (Co-investigator); Gordon R. Bloomberg (Co-investigator); Denise Rodgers (Coordinator); Ellen Albers (1999-2003); James M. Corry (Co-investigator, 1995-2004); Karen DeMuth (2006-2007); Lila Kertz (2005-2007); Valerie Morgan (2004-2007); Cynthia Moseid (2007); Tina Oliver-Welker (1993-2007); Deborah K. White (1993-2007).

Resource centers

Data Coordinating Center, The Johns Hopkins University, Baltimore, MD, USA: James Tonascia (Director); Patricia Belt; Karen Collins; Betty Collison; Ryan Colvin; John Dodge; Michele Donithan; Cathleen Ewing; Rosetta Jackson; Hope Livingston; Jill Meinert; Girlie Reyes; Michael Smith; Alice L. Sternberg; Mark L. Van Natta; AnnetteWagoner; Laura Wilson; Robert Wise; Katherine Yates.

Project Office, National Heart, Lung, and Blood Institute, Bethesda, MD, USA: Virginia Taggart (Project officer); Lois Eggers; James Kiley; Howard Moore; Gang Zheng. Paul Albert (1991-1999); Suzanne Hurd (1991-1999); Sydney Parker (1991-1994); Pamela Randall (1992-2003); Margaret Wu (1991-001).

\section{Committees}

Data and Safety Monitoring Board: Michelle Cloutier (Chair); John Connett; Leona Cuttler; Frank Gilliland. Clarence E. Davis (1993-2003); Howard Eigen (1993-2009, Chair); David Evans (19932007); Meyer Kattan (1993-2007); Rogelio Menendez (1993-2007); F. Estelle R. Simons (1993-2007); Sanford Leikin (1993-1999).

Steering Committee: Robert Strunk (Study chair); N. Franklin Adkinson; Robert Annett (1992-1995, 1997-1999); Bruce Bender; Mary Caesar (1994-1996); Reuben Cherniack (Study chair 1993-2007); Thomas R. DuHamel (1992-1994, 1996-1999); Anne Fuhlbrigge; Hartmut Grasemann; H. William Kelly; Henry Levison (1992-1996); Alan Lincoln (1994-1995); Ian MacLusky (1999-2006); Bennie McWilliams (1992-1998); Curtis L. Meinert; Sydney Parker (1991-1994); Joe Reisman (1991-1999); Denise Rodgers; Kay Seligsohn (1996-1997); Gail G. Shapiro (1991-2006); Marian Sharpe (1993-1994); D Sundstrom (1998-1999); Stanley Szefler; Virginia Taggart; Martha Tata (1996-1998); James Tonascia; Scott Weiss; Barbara Wheeler (1993-1994); Paul Williams; Robert Wise; Robert Zeiger. 


\section{References}

1 Hargreave FE, Ryan G, Thomson NC, et al. Bronchial responsiveness to histamine or methacholine in asthma: measurement and clinical significance. J Allergy Clin Immunol 1981; 68: 347-355.

2 O'Connor G, Sparrow D, Taylor D, et al. Analysis of dose-response curves to methacholine. An approach suitable for population studies. Am Rev Respir Dis 1987; 136: 1412-1417.

3 Burrows B, Sears MR, Flannery EM, et al. Relationships of bronchial responsiveness assessed by methacholine to serum IgE, lung function, symptoms, and diagnoses in 11-year-old New Zealand children. J Allergy Clin Immunol 1992; 90: 376-385.

4 Hancox RJ, Aldridge RE, Cowan JO, et al. Tolerance to beta-agonists during acute bronchoconstriction. Eur Respir J 1999; 14: 283-287.

5 Cisneros C, García-Río F, Romera D, et al. Bronchial reactivity indices are determinants of health-related quality of life in patients with stable asthma. Thorax 2010; 65: 795-800.

6 van der Woude HJ, Winter TH, Aalbers R. Decreased bronchodilating effect of salbutamol in relieving methacholine induced moderate to severe bronchoconstriction during high dose treatment with long acting beta2 agonists. Thorax 2001; 56: 529-535.

7 Singh D, Corradi M, Bindi E, et al. Relief of methacholine-induced bronchospasm with extrafine beclomethasone dipropionate/formoterol in comparison with salbutamol in asthma. Pulm Pharmacol Ther 2012; 25: 392-398.

8 Peters SP, Jones CA, Haselkorn T, et al. Real-world Evaluation of Asthma Control and Treatment (REACT): findings from a national Web-based survey. J Allergy Clin Immunol 2007; 119: 1454-1461.

9 Lane S, Molina J, Plusa T. An international observational prospective study to determine the cost of asthma exacerbations (COAX). Respir Med 2006; 100: 434-450.

10 Akinbami LJ, Moorman JE, Liu X. Asthma prevalence, health care use, and mortality: United States, 2005-2009. Natl Health Stat Report 2011; 32: 1-14.

11 Fuhlbrigge AL, Weiss ST, Kuntz KM, et al. Forced expiratory volume in $1 \mathrm{~s}$ percentage improves the classification of severity among children with asthma. Pediatrics 2006; 118: e347-e355.

12 Rao DR, Gaffin JM, Baxi SN, et al. The utility of forced expiratory flow between $25 \%$ and $75 \%$ of vital capacity in predicting childhood asthma morbidity and severity. J Asthma 2012; 49: 586-592.

13 Shi Y, Aledia AS, Galant SP, et al. Peripheral airway impairment measured by oscillometry predicts loss of asthma control in children. J Allergy Clin Immunol 2013; 131: 718-723.

14 Frey U, Brodbeck T, Majumdar A, et al. Risk of severe asthma episodes predicted from fluctuation analysis of airway function. Nature 2005; 438: 667-670.

15 Childhood Asthma Management Program Research Group. The Childhood Asthma Management Program (CAMP): design, rationale, and methods. Control Clin Trials 1999; 20: 91-120.

16 Childhood Asthma Management Program Research Group. Long-term effects of budesonide or nedocromil in children with asthma. N Engl J Med 2000; 343: 1054-1063.

17 Park HW, Kim TW, Song WJ, et al. Prediction of asthma exacerbations in elderly adults: results of a 1-year prospective study. J Am Geriatr Soc 2013; 61: 1631-1632.

18 The Global Initiative for Asthma. The guideline for asthma management and prevention 2015. http://ginasthma. org/2016-pocket-guide-for-asthma-management-and-prevention/ Date last accessed: June 4, 2015, Date last updated: 2016.

19 Cockcroft DW, Berscheid BA. Slope of the dose-response curve: usefulness in assessing bronchial responses to inhaled methacholine. Thorax 1983; 38: 55-61.

20 Chai H, Farr RS, Froehlich LA, et al. Standardization of bronchial inhalation challenge procedures. J Allergy Clin Immunol 1975; 56: 323-327.

21 O’Brien RM. A caution regarding rules of thumb for variance inflation factors. Qual Quant 2007; 41: 673-690.

22 Marcon A, Cerveri I, Wjst M, et al. Can an airway challenge test predict respiratory diseases? A population-based international study. J Allergy Clin Immunol 2014; 133: 104-110.

23 Juniper EF, Frith PA, Hargreave FE. Airways responsiveness to histamine and methacholine: relationship to minimum treatment to control symptoms of asthma. Thorax 1981; 36: 575-579.

24 Ryan G, Latimer KM, Dolovich J, et al. Bronchial responsiveness to histamine: relationship to diurnal variation of peak flow rate, improvement after bronchodilator, and airway calibre. Thorax 1982; 37: 423-429.

25 Weiss ST, Van Natta ML, Zeiger RS. Relationship between increased airway responsiveness and asthma severity in the childhood asthma management program. Am J Respir Crit Care Med 2000; 162: 50-56.

26 van Essen-Zandvliet EE, Hughes MD, Waalkens HJ, et al. Effects of 22 months of treatment with inhaled corticosteroids and/or beta-2-agonists on lung function, airway responsiveness, and symptoms in children with asthma. Am Rev Respir Dis 1992; 146: 547-554.

27 Haahtela T, Järvinen M, Kava T, et al. Comparison of a beta 2-agonist, terbutaline, with an inhaled corticosteroid, budesonide, in newly detected asthma. N Engl J Med 1991; 325: 388-392.

28 Sutcliffe A, Hollins F, Gomez E, et al. Increased nicotinamide adenine dinucleotide phosphate oxidase 4 expression mediates intrinsic airway smooth muscle hypercontractility in asthma. Am J Respir Crit Care Med 2012; 185: 267-274.

29 Berair R, Hollins F, Brightling C. Airway smooth muscle hypercontractility in asthma. J Allergy (Cairo) 2013; 2013: 185971.

30 Haldar P, Brightling CE, Hargadon B, et al. Mepolizumab and exacerbations of refractory eosinophilic asthma. N Engl J Med 2009; 360: 973-984.

31 Leckie MJ, ten Brinke A, Khan J, et al. Effects of an interleukin-5 blocking monoclonal antibody on eosinophils, airway hyper-responsiveness, and the late asthmatic response. Lancet 2000; 356: 2144-2148.

32 Djukanović R, Wilson SJ, Kraft M, et al. Effects of treatment with anti-immunoglobulin E antibody omalizumab on airway inflammation in allergic asthma. Am J Respir Crit Care Med 2004; 170: 583-593.

33 Sharma S, Litonjua AA, Tantisira KG, et al. Clinical predictors and outcomes of consistent bronchodilator response in the childhood asthma management program. J Allergy Clin Immunol 2008; 122: 921-928.

34 Beasley R, Pearce N, Crane J, et al. Beta-agonists: what is the evidence that their use increases the risk of asthma morbidity and mortality? J Allergy Clin Immunol 1999; 104: S18-S30.

35 Lundgren R, Söderberg M, Hörstedt P, et al. Morphological studies of bronchial mucosal biopsies from asthmatics before and after ten years of treatment with inhaled steroids. Eur Respir J 1988; 1: 883-889. 
36 Goyal M, Jaseja H, Verma N. Increased parasympathetic tone as the underlying cause of asthma: a hypothesis. Med Hypotheses 2010; 74: 661-664.

37 An SS, Bai TR, Bates JHT, et al. Airway smooth muscle dynamics: a common pathway of airway obstruction in asthma. Eur Respir J 2007; 29: 834-860.

38 Kerstjens HAM, Engel M, Dahl R, et al. Tiotropium in asthma poorly controlled with standard combination therapy. N Engl J Med 2012; 367: 1198-1207.

39 Price D, Kaplan A, Jones R, et al. Long-acting muscarinic antagonist use in adults with asthma: real-life prescribing and outcomes of add-on therapy with tiotropium bromide. J Asthma Allergy 2015; 8: 1-13.

40 Pellegrino R, Viegi G, Brusasco V, et al. Interpretative strategies for lung function tests. Eur Respir J 2005; 26: 948-968.

41 Beydon N, Davis SD, Lombardi E, et al. An official American Thoracic Society/European Respiratory Society statement: pulmonary function testing in preschool children. Am J Respir Crit Care Med 2007; 175: 1304-1345.

42 Debley J, Filbrun AG, Subbarao P. Clinical applications of pediatric pulmonary function testing: lung function in recurrent wheezing and asthma. Pediatr Allergy Immunol Pulmonol 2011; 24: 69-76.

43 Lehmann S, Vollset SE, Nygaard HA, et al. Factors determining performance of bronchodilator reversibility tests in middle-aged and elderly. Respir Med 2004; 98: 1071-1079.

44 Ortega VE, Meyers DA. Pharmacogenetics: implications of race and ethnicity on defining genetic profiles for personalized medicine. J Allergy Clin Immunol 2014; 133: 16-26.

45 Nemes S, Jonasson JM, Genell A, et al. Bias in odds ratios by logistic regression modelling and sample size. BMC Med Res Methodol 2009; 9: 56. 